\title{
Why we need knowledge workers to become knowledge citizens
}

\author{
Melanie Sutton \\ Knowledge Officer \\ The IQ Business Group \\ msutton@iqgroup.net
}

Increasingly, the true investment in the knowledge society is not in machines and tools but in the knowledge worker. Without knowledge workers, the machines, no matter how advanced and sophisticated, are unproductive.

But is it the knowledge worker who drives the organizational culture and behaviour that make a knowledge strategy work or is it his or her knowledge citizenship that drives the change in behaviour and acceptance of a culture of sharing that orchestrates a successful knowledge strategy?

We develop our theme of knowledge citizenship by examining why we need our knowledge workers to become knowledge citizens for a successful knowledge strategy.

\section{Knowledge workers}

In 1959, Peter Drucker coined the term knowledge worker. A knowledge worker describes someone who works primarily with information or one who develops and uses knowledge in the workplace. A knowledge worker is a person who has been schooled to use knowledge, theory and concept rather than physical force or manual skill.

The importance of a knowledge worker is confirmed when we think about the concept of knowledge. Knowledge cannot exist without a person. It is always embodied in a person, carried by a person, created, augmented or improved by a person, applied by a person, taught and passed on by a person and used or misused by a person. The shift to the knowledge society therefore puts the knowledge worker at the heart of any knowledge activity, including a knowledge strategy.

\section{What is knowledge work?}

Knowledge work is work performed by humans to generate useful information and knowledge. Knowledge workers access and use data, personal knowledge, organizational knowledge and external knowledge to do this work and employ mental modes and apply significant concentration and attention.

Types of knowledge work include:

- Job specific tasks that may involve knowledge access

- Knowledge building and maintenance that include job specific and general 
knowledge, increasing your knowledge base and network and maintaining individual expertise

- Work management tasks that include managing knowledge work to achieve effective results using time and mental resources efficiently, maintaining work motivation, maintaining readiness to work, plan, sequence and schedule activities, allocating effort and control switching among tasks and managing collaboration

- Knowledge work activities that include acquiring knowledge, that is scanning, monitoring and searching, designing (modelling, planning, organizing, scheduling and authoring), making decisions (formulating, analysing and choosing) and communicating (presenting, persuading and motivating) (Davis 2001).

\section{Knowledge citizenship drives a change in culture and behaviour}

Anybody who has tried to execute a knowledge strategy has been faced with the challenge of knowledge culture and behaviour. Literature will tell you that it is the most challenging aspect of your strategy. Ignore it and you will most certainly fail in your quest - do it right and you can make your organization thrive.

Having a pool of knowledge workers executing 'knowledge work' is not enough. A successful organizational economy needs knowledge citizens, that is, knowledge workers who are willing to get involved in creating the knowledge culture by sharing knowledge, creating new knowledge, networking and participating in knowledge activities.

We understand that citizenship is perceived as a status, suggesting basic social attachment, which implies rights and duties as well as certain privileges. It is also defined as owing allegiance, by which a person is subsequently entitled to be protected. A knowledge worker who embraces the knowledge culture enjoys the benefits of citizenship as he or she is involved in more activities in the organization, has more influence among peers, is seen as a leader and an innovator and enjoys a connectedness with other knowledge citizens that is difficult to replicate. It is possible to have an organization filled with knowledge workers per se, but have no knowledge citizens.

\section{Creating a knowledge citizenship environment}

Just as citizens of a country have certain expectations from their government, so do knowledge citizens have certain expectations in an organization. There must be a connection between what is required of a knowledge citizen and the benefits he or she has in engaging as a citizen, the most of important of which is the environment in which he or she is expected to function.

Often knowledge management initiatives fail to produce results because there is a disconnection between what is expected and the environment in which it is inculcated. For example, we may encourage our knowledge workers to participate in knowledge sharing activities, but do not give them company time in which to engage in these activities. Alternatively, we do not spend the necessary monies to make this collaboration possible. Even worse, we may throw money at a problem and expect it to be solved, whereas a visit from the CEO or receiving recognition in an organization would have a far better effect.

Knowledge strategies should take into account the environment in which knowledge culture and behaviour will be developed and put the necessary processes that make it easy for knowledge workers to embrace citizenship in place. The benefits of citizenship, such as status, reward, recognition or personal development must be made evident.

\section{Communities of practice as knowledge citizen hubs}


Communities of practice are generally hubs of energy where true knowledge citizens congregate. They often have status in an organization. Members create social attachments with each other, have a sense of purpose, are committed to creating a culture of sharing and are committed to their role in the community. They understand the benefits of belonging to a group who share knowledge and collaborate for the benefit of everyone.

Communities are powerful mechanisms to encourage knowledge citizenship and are, in fact, a very healthy way in which the benefits of embracing the knowledge society that we find ourselves in are demonstrated. However, the danger lies in not creating the right environment for these communities to thrive.

For management and knowledge workers to embrace citizenship, they need to believe in something tangible, such as a formula that can be patented, step-by-step instructions, a computer-driven process or a neat new database, since this is what they are accustomed to. Communities of practice provide the tangible entity, the safety net, the social network, the human element that helps knowledge workers to connect quicker and to multiply the power of their individual minds collaboratively.

\title{
Conclusion
}

Organizations must decide how their knowledge strategy manages their knowledge workers. Are they just a pool of intellectual capital, raw material for the knowledge economy, or are they valuable citizens who engage and embrace the knowledge culture and are the key to making the knowledge strategy a reality?

If knowledge management is considered a critical corporate strategy, why are we happy to have knowledge workers and not knowledge citizens? Knowledge citizenship is a personal issue, it is a decision someone takes, it is a behaviour that someone embraces and actively carries out. Organizations should recognize that it is a serious commitment and endeavour to create environments that encourage knowledge citizenship.

\section{References and sources}

Ash, J. 2001. Why isn't KM working - too much emphasis on technology and too little trust in the workplace. [Online.] Available WWW:

http://www.kwork.org/White_Papers/work.html.

Davis, B. 2001. An emerging issue: knowledge worker productivity and information technology. [Online.] Available WWW:

http://proceedings.informingscience.org/IS2001Proceedings/Overheads/Davis\%

20KrakowTalkKnowledgeWork.ppt

Drucker, P.F. 2003. The essential Drucker. New York Harper: Collins

\begin{abstract}
About the author
Melanie Sutton (BA, Postgraduate Diploma in Information Management) is a Senior Principal Consultant in the Enterprise Content Management Discipline and a member of Intellectual Property Forum at The IQ Business Group, South Africa.
\end{abstract}

\section{Disclaimer}

Articles published in SAJIM are the opinions of the authors and do not necessarily reflect the opinion of the Editor, Board, Publisher, Webmaster or the Rand Afrikaans University. The user hereby waives any claim 
he/she/they may have or acquire against the publisher, its suppliers, licensees and sub licensees and indemnifies all said persons from any claims, lawsuits, proceedings, costs, special, incidental, consequential or indirect damages, including damages for loss of profits, loss of business or downtime arising out of or relating to the user's use of the Website.

ISSN 1560-683X

Published by InterWord Communications for Department of Information and Knowledge Management, University of Johannesburg 